\title{
Adverse effects of delayed antimicrobial treatment and surgical source control in adults with sepsis: results of a planned secondary analysis of a cluster-randomized controlled trial
}

\author{
Hendrik Rüddel ${ }^{1,2}$, Daniel O. Thomas-Rüddel ${ }^{1,2}$, Konrad Reinhart $^{3,4}$, Friedhelm Bach ${ }^{5}$, Herwig Gerlach $^{6}$, \\ Matthias Lindner ${ }^{7}$, John C. Marshall ${ }^{8}$, Philipp Simon ${ }^{9}$, Manfred Weiss ${ }^{10}$, Frank Bloos ${ }^{1,2}$, \\ Daniel Schwarzkopf ${ }^{1,2,11^{*}}$ (i) and the MEDUSA study group
}

\begin{abstract}
Background: Timely antimicrobial treatment and source control are strongly recommended by sepsis guidelines, however, their impact on clinical outcomes is uncertain.

Methods: We performed a planned secondary analysis of a cluster-randomized trial conducted from July 2011 to May 2015 including forty German hospitals. All adult patients with sepsis treated in the participating ICUs were included. Primary exposures were timing of antimicrobial therapy and delay of surgical source control during the first $48 \mathrm{~h}$ after sepsis onset. Primary endpoint was 28-day mortality. Mixed models were used to investigate the effects of timing while adjusting for confounders. The linearity of the effect was investigated by fractional polynomials and by categorizing of timing.
\end{abstract}

Results: Analyses were based on 4792 patients receiving antimicrobial treatment and 1595 patients undergoing surgical source control. Fractional polynomial analysis identified a linear effect of timing of antimicrobials on 28-day mortality, which increased by $0.42 \%$ per hour delay (OR with $95 \% \mathrm{Cl} 1.019[1.01,1.028], p \leq 0.001$ ). This effect was significant in patients with and without shock $(\mathrm{OR}=1.018[1.008,1.029]$ and $1.026[1.01,1.043]$, respectively). Using a categorized timing variable, there were no significant differences comparing treatment within $1 \mathrm{~h}$ versus $1-3 \mathrm{~h}$, or $1 \mathrm{~h}$ versus 3-6 h. Delays of more than $6 \mathrm{~h}$ significantly increased mortality $(\mathrm{OR}=1.41[1.17,1.69])$. Delay in antimicrobials also increased risk of progression from severe sepsis to septic shock (OR per hour: $1.051[1.022,1.081], p \leq 0.001)$. Time to surgical source control was significantly associated with decreased odds of successful source control $(\mathrm{OR}=0.982$ $[0.971,0.994], p=0.003)$ and increased odds of death $(\mathrm{OR}=1.011[1.001,1.021] ; p=0.03)$ in unadjusted analysis, but not when adjusted for confounders ( $O R=0.991[0.978,1.005]$ and $O R=1.008[0.997,1.02]$, respectively). Only, among patients with septic shock delay of source control was significantly related to risk-of death (adjusted OR=1.013 [1.001, $1.026], p=0.04)$.

\footnotetext{
*Correspondence: Daniel.Schwarzkopf@med.uni-jena.de

${ }^{1}$ Integrated Research and Treatment Center - Center for Sepsis Contro and Care (CSCC), Jena University Hospital, Am Klinikum 1, 07747 Jena, Germany

Full list of author information is available at the end of the article Collaborating author group: MEDUSA study group, E-Mail: Frank.Bloos@ med.uni-jena.de
} permits use, sharing, adaptation, distribution and reproduction in any medium or format, as long as you give appropriate credit to the original author(s) and the source, provide a link to the Creative Commons licence, and indicate if changes were made. The images or other third party material in this article are included in the article's Creative Commons licence, unless indicated otherwise in a credit line to the material. If material is not included in the article's Creative Commons licence and your intended use is not permitted by statutory regulation or exceeds the permitted use, you will need to obtain permission directly from the copyright holder. To view a copy of this licence, visit http://creativecommons.org/licenses/by/4.0/. The Creative Commons Public Domain Dedication waiver (http://creativeco mmons.org/publicdomain/zero/1.0/) applies to the data made available in this article, unless otherwise stated in a credit line to the data. 
Conclusions: Our findings suggest that management of sepsis is time critical both for antimicrobial therapy and source control. Also patients, who are not yet in septic shock, profit from early anti-infective treatment since it can prevent further deterioration. Trial registration ClinicalTrials.gov (NCT01187134). Registered 23 August 2010, NCT01187134

Keywords: Sepsis, Infection control, Anti-biotic agents, Time-to-treatment, Patient care bundles, Surgical source control

\section{Background}

Sepsis is a life-threatening organ dysfunction caused by a dysregulated host response to infection [1]. International clinical practice guidelines define sepsis as an emergency, demanding treatment with broad spectrum antibiotics [2]. They recommend antimicrobial treatment within $1 \mathrm{~h}$ in patients with septic shock or a high likelihood of sepsis, and treatment within $3 \mathrm{~h}$ in patients with possible sepsis without shock and persisting concerns of infection [2]. Evidence for the effect of timing of antimicrobial therapy on mortality is contradictive [3-6].

It is argued that prompt antimicrobials within the first hours might be warranted for the most severely ill patients with septic shock, only.[5, 7, 8]. Therefore, current guidelines reduced the evidence rating for immediate treatment from moderate to low in septic shock and from moderate to very low in sepsis without shock $[2,9]$. However, current evidence is based on systematic reviews that comprised numerous studies with several acknowledged methodological flaws $[3,4,6]$. These include usage of routine databases without prospective inclusion of patients with sepsis, non-physiologic definition of time zero-e.g. by emergency triage time or first sepsis-related treatment, not adequately adjusting for confounders, and not investigating treatment effects separately for patients without and with septic shock $[5,8]$.

Guidelines also advice as best practice to conduct surgical source control as soon as medically and logistically possible [2]. However, this best practice statement is based on few studies only, mostly conducted among samples of single specific disease entities-like necrotizing fasciitis-and with diverging results [10-14].

To overcome these limitations, we analysed a large data set from the prospective cluster-randomized quality improvement MEDUSA trial to assess the impact of timing of antimicrobial therapy and source control on mortality.

\section{Methods}

\section{Study design and setting}

The aim of this observational cohort study was to investigate the effect of timing of anti-infective treatment on outcomes in patients with severe sepsis. Primary outcome was 28-day mortality. Secondary outcomes were hospital length-of-stay of survivors, progression from severe sepsis to septic shock, and success of surgical source control. Primary exposures were timing of antimicrobial therapy and timing of surgical source control. This study was conducted as a planned secondary analysis using data from the two-arm cluster-randomized controlled MEDUSA trial (Medical Education for Sepsis Source Control and Antibiotics, ClinicalTrials.gov Identifier NCT01187134) [15].

The MEDUSA trial aimed to improve anti-infective measures for patients with sepsis. Hospitals were randomized to either an intervention group receiving a multifaceted educational intervention, or a control group receiving only standard lectures on sepsis treatment. Results from this trial, which has been conducted from July 2011 to May 2013, have been reported previously [15]. The sample of the now reported secondary analysis additionally includes data gathered during a second intervention phase conducted from September 2013 to May 2015, which implemented an enhanced version of the educational intervention among former control hospitals. Intervention group and study phase are controlled as a possible confounder in the current observational secondary analysis, but the evaluation of the enhanced intervention itself will be reported in a separate article. A convenience sample of 40 German hospitals involved in primary sepsis care was included. Patients with severe sepsis were prospectively included by intensive care physicians on the participating intensive care units. All sepsis diagnoses were reevaluated on day 5 after screening; only cases with confirmed diagnoses were included to the study. Data were abstracted from the medical records and documented using the data management software OpenClinica ${ }^{\circledR}$ (OpenClinica, LLC, Waltham, MA, USA). This study was performed in line with the principles of the Declaration of Helsinki and approved by the local ethics committees responsible for a participating institution. The need for informed consent was waived since the interventions comprised quality improvement measures.

\section{Patient sample}

All consecutive adult patients treated in the ICU for proven or suspected infection with at least one new organ dysfunction related to the infection were eligible for inclusion. Organ dysfunctions were defined as follows: acute encephalopathy, thrombocytopenia defined 
as a platelet count $<100,000 / \mu \mathrm{l}$ or a drop in platelet count $>30 \%$ within $24 \mathrm{~h}$, arterial oxygen partial pressure $<10 \mathrm{kPa}(75 \mathrm{mmHg})$ when breathing room air or partial pressure of arterial oxygen/fraction of inspired oxygen ratio $<33 \mathrm{kPa}(<250 \mathrm{mmHg})$, renal dysfunction defined as oliguria (diuresis $\leq 0.5 \mathrm{ml} / \mathrm{kg}$ body weight/ hour) despite adequate fluid resuscitation or an increase of serum creatinine more than twice the local reference value, metabolic acidosis with a base excess $<-5 \mathrm{mmol} / \mathrm{l}$ or a serum lactate $>1.5$ times the local reference value, and arterial hypotension defined as systolic arterial blood pressure $<90 \mathrm{mmHg}$ or mean arterial blood pressure $<70 \mathrm{mmHg}$ for $>1 \mathrm{~h}$ despite adequate fluid loading or vasopressor therapy at any dosage to maintain higher blood pressures [16]. SIRS-criteria did not need to be present to define sepsis. Patients were excluded, if there was a therapy limitation at the onset of sepsis, if they were not treated in the participating ICU after sepsis diagnosis, or if sepsis therapy had already been started in another hospital.

Preliminary findings on the effects of timing of antimicrobials and source control on mortality were presented in a previous publication [15]. These preliminary analyses were conducted based on cases included during the first intervention phase of the trial. The now reported detailed analyses have not been conducted before and are based on additional patients included in the second intervention phase. They surpass previous analyses by excluding patients receiving anti-infective treatment before first organ dysfunction to prevent bias, excluding indicators of illness severity assessed after sepsis onset from the set of considered confounders, investigating the linearity of the effect of timing by fractional polynomials, investigating the effect separately in cases with and without shock as well as other subgroups, and additionally to mortality investigating the effect on progression to shock, success of source control, and hospital length-of-stay.

\section{Outcomes and exposures}

The primary outcome was 28-day mortality. Secondary outcomes were hospital length-of-stay for survivors, success of source control, and progression to septic shock. Success of source control was assessed by the treating physicians and to their own discretion; blinding to outcome was not intended by the study protocol. Septic shock was defined by the need to administer vasoactive agents to maintain mean arterial pressure $\geq 70 \mathrm{mmHg}$. Presence of shock was assessed during two timeframes: during the first $12 \mathrm{~h}$ after sepsis onset, and between 12 and $24 \mathrm{~h}$ after sepsis onset. Therefore, we defined progression to septic shock as new onset of septic shock between 12 and $24 \mathrm{~h}$ among those patients not in shock during the first $12 \mathrm{~h}$.
Onset of sepsis was defined as the earliest time of the first infection-related organ dysfunction as documented in the patient's medical record. All available information was assessed to identify time zero, including patient charts from the general ward or emergency department. Primary exposures were timing of antimicrobial therapy and timing of surgical source control. Timing was used as continuous variable, however excluding cases with times $<0 \mathrm{~h}$ and times $>48 \mathrm{~h}$. Cases with times $<0 \mathrm{~h}$ were excluded from the respective analysis, since these cases would represent a very specific subsample: patients, who develop infection related organ dysfunction and the need of critical care despite anti-infective treatment before sepsis onset. Cases with timing $>48 \mathrm{~h}$ were excluded as outliers. Timing of antimicrobials was measured as first administration. Timing of source control was defined by the first cut. We also investigated the effect of timing of surgical source control on success of surgical source control, and of timing to antimicrobial treatment and timing of surgical source control on the risk of progression to septic shock, as well as the effects of success of surgical source control on mortality and length-of-stay.

\section{Statistical analysis}

Baseline characteristics of patients were statistically described stratified by timing of antimicrobial therapy and timing of surgical source control. Logistic regressions were used to analyse effects of exposures on mortality, success of source control, and progression to septic shock. Effects on hospital length-of-stay were analysed using linear regression after log-transformation of length-of-stay. Since it was suggested that the effect of timing of treatment on mortality might be non-linear [5], we used two strategies to investigate the linearity of the effect: first, timing was analysed as a categorical variable including start of treatment within one hour, one to three hours, three to six hours, or after more than six hours to allow comparison with previous research [17]; second, we used fractional polynomials which operationalize the functional form of an effect and test for deviations from linearity [18].

All regression analyses adjusted for covariates. Covariates for risk-adjustment were chosen a priori as potential confounders of the effects between timing of treatment and outcomes based on clinical experience and previous studies $[15,19-21]$. These variables included age and gender, origin of infection, location of the patient at the onset of sepsis, focus of infection, microbiological confirmation of infection, study phase (trial vs. surveillance phase), and the group the hospital was randomized to (intervention vs. control during the trial phase). To measure severity of critical illness after sepsis onset, vasopressor use within the first $12 \mathrm{~h}$, as well as the maximum 
values within the first $24 \mathrm{~h}$ after sepsis onset of SAPS-II, lactate in $\mathrm{mmol} / \mathrm{l}$, platelets, and base excess were used $[22,23]$. Two risk-adjustment models were developed: In the primary analyses covariates on the severity of critical illness during the first $24 \mathrm{~h}$ were not included, since these might themselves be influenced by timing to treatment, as well as in response to recent arguments that effects of timing of antimicrobial therapy might only be present after statistical adjustment for severity of illness [24]. Covariates on the severity of critical illness were then included in the second risk model to conduct sensitivity analyses. Both resulting models showed adequate calibration (Hosmer-Lemeshow goodness-of-fit test: $p=0.077$ and $p=0.219$, Additional File 1: SFig. 1); including covariates on the severity of critical illness increased discrimination and explained variance (area under the receiver operating characteristic: 0.68 vs. $0.76 ; R^{2}: 0.08$ vs. 0.18 ). STables 1 and 2 in Additional File 2 present the effects of individual risk-factors. To control for clustering, regression analyses were done by mixed models with a random intercept.

To analyse the combined effects of delay to antimicrobial therapy and delay to surgical source control on mortality, both were included in one logistic regression and an interaction effect between the two was tested.

\section{Subgroup and sensitivity analyses}

To test, if the effect of timing of treatment on mortality was different comparing subgroups, interaction terms between timing and pre-specified effect modifiers were introduced into the regression models. Possible modifiers were chosen based on previous research [19]: Vasopressor use within the first $12 \mathrm{~h}$ after onset of sepsis (yes vs. no), origin of infection (community acquired, nosocomial on ICU or intermediate care unit, nosocomial on general ward), location of the patient at onset of sepsis (ICU or intermediate care unit, ambulance service or emergency department, general ward, operating room), microbiological confirmation of infection (yes vs. no), bacteraemia and type of identified pathogen (gram positive, gram negative, other or several pathogens, no pathogen detected, no blood culture taken), change of antimicrobial therapy within 5 days (escalation, de-escalation, no change), surgical source control conducted (yes vs. no; in analyses on timing of antimicrobials), or success of surgical source control (yes vs. no; in analysis on timing of surgical source control), respectively.

As a sensitivity analysis, the effects of timing of treatment on mortality were assessed while also adjusting for covariates measuring the severity of critical illness within the first $24 \mathrm{~h}$ after onset of sepsis.

All analyses were conducted at a significance level of $\alpha<0.05$ using the statistical software $R$, version 4.1.2 (R
Foundation for Statistical Computing, Vienna, Austria). The amount of missing values on exposures, outcomes, and confounders for the primary analyses and subgroup analyses was roughly $\leq 5 \%$. Therefore, analysis of complete data was regarded as suitable strategy for treating missing data [25].

\section{Results}

\section{Characteristics of patients and time to treatment}

Characteristics of participating hospitals are presented in Additional File 2: STable 3. Overall, 6576 patients with severe sepsis or septic shock were included, of whom 6514 received antimicrobial treatment for the infection that caused sepsis; antibiotics were started after the first organ dysfunction and within $48 \mathrm{~h}$ in 4792 patients, of which 1687 (35\%) had been included in the second intervention phase of the trial and not been analysed before (see Additional File 1: SFig. 2 for study flow chart and Additional File 2: STable 4 for characteristics of excluded patients). These patients showed a mortality of $32 \%$. Median age was 70 years, $62 \%$ were male, $47 \%$ had a community acquired infection; respiratory infections were the most common focus (43\%), 75\% received vasopressors during the first $12 \mathrm{~h}$ after sepsis onset (Table 1). Surgical source control was undertaken among 2562 patients, 1595 of whom received it after the first organ dysfunction and within $48 \mathrm{~h}$ (see Additional File 1: SFig. 2 for study flow chart and Additional File 2: STable 5 for characteristics of excluded patients). These patients showed a mortality of $33 \%$. The most common focus was abdominal infection (73\%), and $85 \%$ received vasopressors during the first $12 \mathrm{~h}$ (Table 2).

Median delay until antimicrobial therapy was $150 \mathrm{~min}$ (1st quartlile: 60, 3rd quartile: 378.5), 3481 (73\%) of patients received antimicrobials after more than $1 \mathrm{~h}$. Median delay to surgical source control was $275 \mathrm{~min}$ (1st quartile: 81 , 3rd quartile: 810$), 671$ (42\%) patients underwent source control after more than $6 \mathrm{~h}$ (Additional File 1: SFig. 3 a-d). Baseline characteristics of patients stratified by timing of antimicrobial therapy and surgical source control are presented in Tables 1 and 2, respectively. Patients who received antimicrobial therapy within the first hour and patients who received surgical source control within the first $6 \mathrm{~h}$ more often had a community acquired infection when compared to patients with delayed therapy.

\section{Effects of time to treatment on mortality}

Without risk-adjustment, time between onset of sepsis and start of antimicrobial therapy had a significant effect on 28-day mortality with an unadjusted OR of 1.02 (95\% CI 1.012, 1.029; $p \leq 0.001)$. The effect was also significant when adjusted for covariates (adjusted OR per 
Table 1 Baseline characteristics of patients stratified by timing of start of antimicrobial treatment

\begin{tabular}{|c|c|c|c|c|c|}
\hline \multirow[t]{2}{*}{ Variable } & \multirow{2}{*}{$\begin{array}{l}\text { No. of patients } \\
\text { with complete } \\
\text { data }\end{array}$} & \multirow[t]{2}{*}{ All patients $(N=4792)$} & \multicolumn{3}{|c|}{ Timing of antimicrobial therapy } \\
\hline & & & Within $1 \mathrm{~h}(N=1311)$ & More than $1 \mathrm{~h}(N=3481)$ & $p$ value \\
\hline $\begin{array}{l}\text { Time to beginning of antimicrobial } \\
\text { therapy (minutes) }\end{array}$ & 4792 & $150[60,378.5]$ & $30[15,50]$ & $240[120,518]$ & - \\
\hline Age & 4791 & $70[59,77]$ & $71[60,77]$ & $70[59,77]$ & 0.435 \\
\hline Sex: male & 4792 & $2986(62.3 \%)$ & $800(61 \%)$ & $2186(62.8 \%)$ & 0.27 \\
\hline Origin of infection: Community acquired & 4791 & $2273(47.4 \%)$ & 779 (59.4\%) & $1494(42.9 \%)$ & $\leq 0.001$ \\
\hline Nosocomial (ICU/IMC) & & $1112(23.2 \%)$ & $208(15.9 \%)$ & $904(26 \%)$ & \\
\hline Nosocomial (general ward) & & $1406(29.3 \%)$ & $324(24.7 \%)$ & $1082(31.1 \%)$ & \\
\hline Location at onset of sepsis: ICU & 4792 & $2233(46.6 \%)$ & $559(42.6 \%)$ & $1674(48.1 \%)$ & $\leq 0.001$ \\
\hline Emergency department & & $948(19.8 \%)$ & $333(25.4 \%)$ & $615(17.7 \%)$ & \\
\hline Operating room & & $428(8.9 \%)$ & $167(12.7 \%)$ & $261(7.5 \%)$ & \\
\hline General ward & & $692(14.4 \%)$ & $127(9.7 \%)$ & $565(16.2 \%)$ & \\
\hline Ambulance service & & $211(4.4 \%)$ & $48(3.7 \%)$ & $163(4.7 \%)$ & \\
\hline$I M C$ & & $280(5.8 \%)$ & 77 (5.9\%) & $203(5.8 \%)$ & \\
\hline Focus of infection: respiratory & 4789 & $2057(43 \%)$ & $510(38.9 \%)$ & $1547(44.5 \%)$ & $\leq 0.001$ \\
\hline Focus of infection: abdominal & 4789 & $1657(34.6 \%)$ & $464(35.4 \%)$ & $1193(34.3 \%)$ & 0.474 \\
\hline Focus of infection: urogenital & 4789 & $695(14.5 \%)$ & $209(16 \%)$ & $486(14 \%)$ & 0.089 \\
\hline $\begin{array}{l}\text { Focus of infection: bones/soft tissue/ } \\
\text { wound }\end{array}$ & 4789 & $531(11.1 \%)$ & $154(11.8 \%)$ & $377(10.8 \%)$ & 0.38 \\
\hline Focus of infection: other/unknown & 4789 & $644(13.4 \%)$ & $161(12.3 \%)$ & $483(13.9 \%)$ & 0.154 \\
\hline Infection microbiologically confirmed & 4781 & $3514(73.5 \%)$ & $965(73.7 \%)$ & $2549(73.4 \%)$ & 0.854 \\
\hline Bacteremia: Gram positive & 4754 & $806(17 \%)$ & $223(17.2 \%)$ & $583(16.9 \%)$ & 0.005 \\
\hline Gram negative & & $712(15 \%)$ & $226(17.4 \%)$ & $486(14.1 \%)$ & \\
\hline Other/several & & $166(3.5 \%)$ & $41(3.2 \%)$ & $125(3.6 \%)$ & \\
\hline No pathogen detected & & $2281(48 \%)$ & $627(48.3 \%)$ & 1654 (47.9\%) & \\
\hline No blood culture taken & & 789 (16.6\%) & $182(14 \%)$ & $607(17.6 \%)$ & \\
\hline $\begin{array}{l}\text { Vasopressor use within } 12 \mathrm{~h} \text { after first } \\
\text { organ dysfunction }\end{array}$ & 4781 & $3595(75.2 \%)$ & $982(75.2 \%)$ & $2613(75.2 \%)$ & 1 \\
\hline
\end{tabular}

Descriptive statistics given as $\mathrm{N}$ (\%) or median [interquartile range]. $p$ values obtained by Mann-Whitney-U test, Fisher's exact test or Pearson's Chi-squared test, as appropriate

ICU: intensive care unit; IMC: intermediate care unit

hour with $95 \%$ CI 1.019 [1.01, 1.028], $p \leq 0.001)$ and corresponded to an increase of $0.42 \%$ per hour delay for a typical patient (Fig. 1 a). Pairwise comparisons of discrete time intervals with antimicrobial treatment within $1 \mathrm{~h}$ revealed non-significant effects for timing of $1-3 \mathrm{~h}$ $(\mathrm{OR}=1.14[0.95,1.36])$ and $3-6 \mathrm{~h}(\mathrm{OR}=1.04[0.85,1.27])$ but a significantly increased odds of hospital mortality for time greater than $6 \mathrm{~h}(\mathrm{OR}=1.36$ [1.12, 1.63], Fig. 2).

Delay of surgical source control showed a significant relation to an increase in mortality by an unadjusted $\mathrm{OR}$ of $1.011(1.001,1.021 ; p=0.03)$, but this relation failed to reach statistical significance when covariates were adjusted (Fig. 1 b, OR $=1.008$ [0.997, 1.02], $p=0.143$ ). Also pairwise comparisons of discrete time intervals did not show significant effects when adjusted for confounders (overall $p=0.22$, Fig. 2).
Combined effects of timing of antimicrobial therapy and timing of surgical source control were investigated among 1222 patients, which had received both treatments between sepsis onset and $48 \mathrm{~h}$. There was no significant interaction effect between both (OR of 1 [0.998, $1.001] ; p=0.577$ ), meaning that delay in one treatment did not change the effect of a delay in the other treatment, but both acted additively (see Additional File 2: STable 6).

\section{Effects of time to treatment on success of source control and progression to septic shock}

Source control was successful in 1333 of 1595 patients (83.6\%). Successful source control was associated with decreased mortality $(\mathrm{OR}=0.12[0.08,0.16], p \leq 0.001$, Fig. 2). A delay of surgical source control was associated with a reduced rate of successful source control when not adjusted for confounders (OR per hour: 0.982 [0.971, 
Table 2 Baseline characteristics of patients stratified by timing of surgical source control

\begin{tabular}{|c|c|c|c|c|c|}
\hline \multirow[t]{2}{*}{ Variable } & \multirow{2}{*}{$\begin{array}{l}\text { No. of patients } \\
\text { with complete } \\
\text { data }\end{array}$} & \multirow[t]{2}{*}{ All patients $(N=1595)$} & \multicolumn{3}{|c|}{ Timing of surgical source control } \\
\hline & & & Whithin $6 \mathrm{~h}(N=924)$ & More than $6 \mathrm{~h}(N=671)$ & $p$ value \\
\hline Time to surgical source control (minutes) & 1595 & $275[81,810]$ & $109[38,225]$ & $950[593,1500]$ & - \\
\hline Age & 1595 & $70[59,77]$ & $70[60,78]$ & $69[59,76]$ & 0.152 \\
\hline Sex: male & 1595 & $934(58.6 \%)$ & $538(58.2 \%)$ & $396(59 \%)$ & 0.758 \\
\hline Origin of infection: Community acquired & 1595 & 795 (49.8\%) & $507(54.9 \%)$ & $288(42.9 \%)$ & $\leq 0.001$ \\
\hline Nosocomial (ICU/IMC) & & $292(18.3 \%)$ & $111(12 \%)$ & $181(27 \%)$ & \\
\hline Nosocomial (general ward) & & $508(31.8 \%)$ & $306(33.1 \%)$ & $202(30.1 \%)$ & \\
\hline Location at onset of sepsis: ICU & 1595 & $573(35.9 \%)$ & $255(27.6 \%)$ & $318(47.4 \%)$ & $\leq 0.001$ \\
\hline Emergency department & & $298(18.7 \%)$ & $170(18.4 \%)$ & $128(19.1 \%)$ & \\
\hline Operating room & & $344(21.6 \%)$ & $324(35.1 \%)$ & $20(3 \%)$ & \\
\hline General ward & & $232(14.5 \%)$ & $107(11.6 \%)$ & $125(18.6 \%)$ & \\
\hline Ambulance service & & $39(2.4 \%)$ & $22(2.4 \%)$ & $17(2.5 \%)$ & \\
\hline IMC & & $109(6.8 \%)$ & $46(5 \%)$ & $63(9.4 \%)$ & \\
\hline Focus of infection: respiratory & 1595 & $171(10.7 \%)$ & $69(7.5 \%)$ & $102(15.2 \%)$ & $\leq 0.001$ \\
\hline Focus of infection: abdominal & 1595 & $1161(72.8 \%)$ & $705(76.3 \%)$ & $456(68 \%)$ & $\leq 0.001$ \\
\hline Focus of infection: urogenital & 1595 & $121(7.6 \%)$ & $60(6.5 \%)$ & $61(9.1 \%)$ & 0.056 \\
\hline $\begin{array}{l}\text { Focus of infection: bones/soft tissue/ } \\
\text { wound }\end{array}$ & 1595 & $272(17.1 \%)$ & $135(14.6 \%)$ & 137 (20.4\%) & 0.003 \\
\hline Focus of infection: other/unknown & 1595 & $117(7.3 \%)$ & $59(6.4 \%)$ & $58(8.6 \%)$ & 0.098 \\
\hline Infection microbiologically confirmed & 1592 & $1239(77.8 \%)$ & $696(75.6 \%)$ & $543(80.9 \%)$ & 0.012 \\
\hline Bacteremia: gram positive & 1587 & $224(14.1 \%)$ & $99(10.8 \%)$ & $125(18.7 \%)$ & $\leq 0.001$ \\
\hline Gram negative & & $206(13 \%)$ & $117(12.7 \%)$ & $89(13.3 \%)$ & \\
\hline Other/several & & $54(3.4 \%)$ & $29(3.2 \%)$ & $25(3.7 \%)$ & \\
\hline No pathogen detected & & 720 (45.4\%) & $421(45.9 \%)$ & $299(44.7 \%)$ & \\
\hline No blood culture taken & & 383 (24.1\%) & $252(27.5 \%)$ & 131 (19.6\%) & \\
\hline $\begin{array}{l}\text { Vasopressor use within } 12 \mathrm{~h} \text { after first } \\
\text { organ dysfunction }\end{array}$ & 1590 & 1346 (84.7\%) & 830 (90.2\%) & $516(77 \%)$ & $\leq 0.001$ \\
\hline
\end{tabular}

Descriptive statistics given as $N$ (\%) or median [interquartile range]. $p$-values obtained by Mann-Whitney-U test, Fisher's exact test or Pearson's Chi-squared test as appropriate

ICU: intensive care unit; IMC: intermediate care unit

0.994], $p=0.003)$, but the adjusted effect was not significant $(\mathrm{OR}=0.991[0.978,1.005], p=0.197$, Additional File 1: SFig. 4).

A delay in antimicrobial treatment was associated with a higher risk of progression to septic shock between 12 and $24 \mathrm{~h}$ after sepsis onset $(\mathrm{OR}=1.051$ [1.022, 1.081] per hour, $p \leq 0.001$, based on 1129 patients, of which 291 (25.8\%) progressed to shock, Fig. 1c). Unexpectedly, time to surgical source control did not show a linear relation to the risk of progression to septic shock, but a reverse-ushaped effect, with the risk increasing until $12 \mathrm{~h}$ and then decreasing again $(p=0.002$, based on 193 cases, of which 82 progressed to shock, Fig. 1d).

\section{Effects of time to treatment on hospital length-of-stay of hospital survivors}

Length-of-stay for hospital survivors was longer if the start of antimicrobial therapy or surgical source control was delayed (ratio of geometric means with 95\% CI $1.02[1,1.03], p=0.023$, and 1.04 [1.01, 1.07], $p=0.003$, respectively, Additional File 2: STable 7). Successful source control was associated with reduced hospital length of stay $(0.72[0.61,0.86], p \leq 0.001)$.

\section{Subgroup analyses}

Delayed antimicrobial treatment was associated with increased odds of death both among patients not receiving vasopressors within the first $12 \mathrm{~h}$ (adjusted $\mathrm{OR}=1.026[1.01,1.043]$ per hour, $p=0.002)$ and patients receiving vasopressors (adjusted OR $=1.018$ $[1.008,1.029], p \leq 0.001$; test of difference between odds-ratios: $p=0.406$ ). A delay of surgical source control was significantly related to increased mortality only 


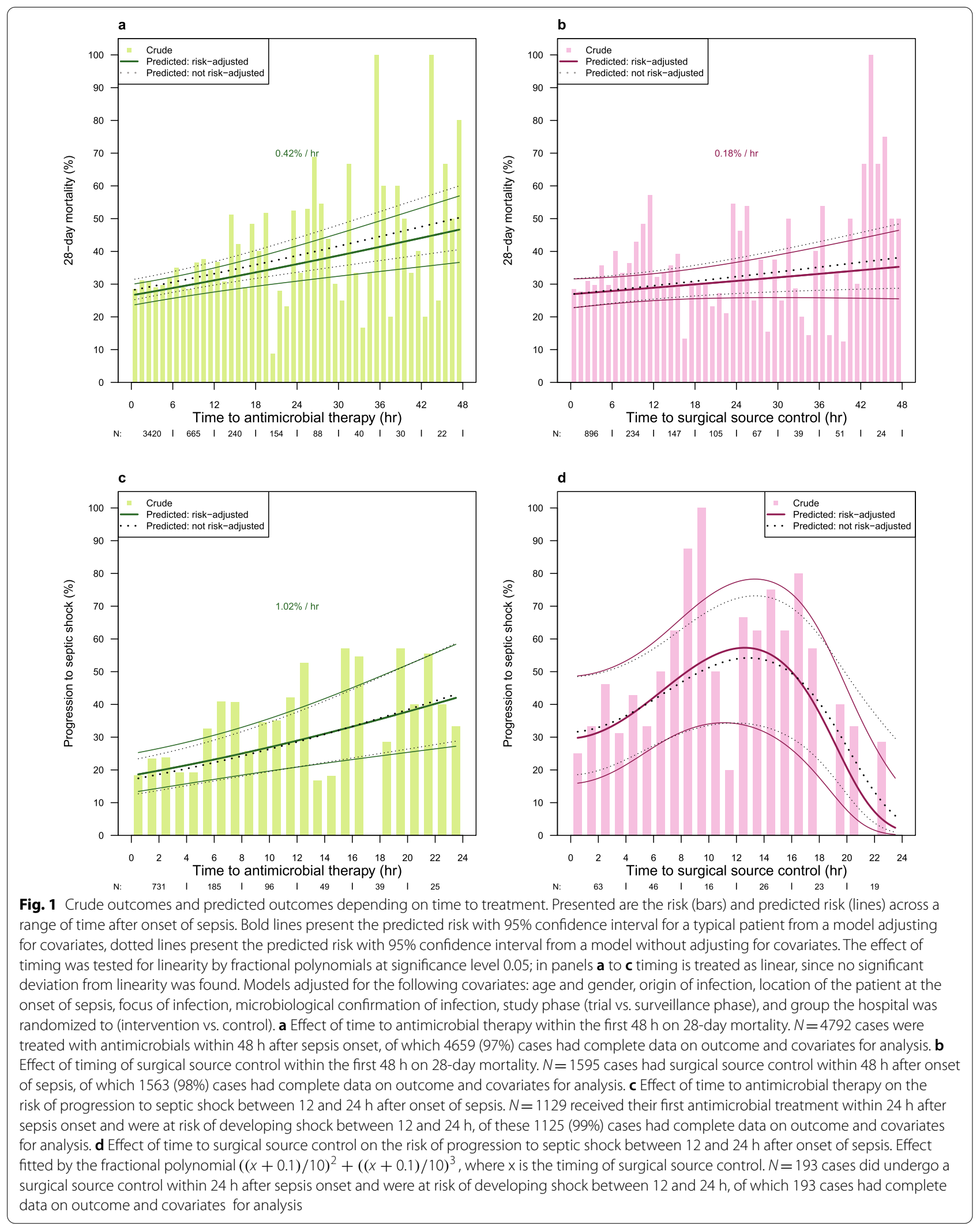




\begin{tabular}{|c|c|c|c|c|c|c|}
\hline Predictor & No. of patients & $\begin{array}{l}\text { Observed } \\
\text { mortality }\end{array}$ & $\begin{array}{r}\text { Risk-adjusted } \\
\text { mortality }\end{array}$ & OR $(95 \% \mathrm{Cl})$ & $\begin{array}{l}\text { Decreasing Increasing } \\
\text { mortality mortality }\end{array}$ & P-value \\
\hline Timing of antimicrobial therapy & $4659 / 4792$ & & & & & $0.008^{*}$ \\
\hline $0-1 \mathrm{hr}$ & & $364 / 1270(28.7)$ & $25.3(22,28.9)$ & 1 & & \\
\hline $1-3 \mathrm{hrs}$ & & $418 / 1352(30.9)$ & $27.8(24.4,31.6)$ & $1.14(0.95,1.36)$ & $\because-1$ & 0.149 \\
\hline $3-6 \mathrm{hrs}$ & & $255 / 836(30.5)$ & $26(22.3,30.2)$ & $1.04(0.85,1.27)$ & $\mapsto-1$ & 0.715 \\
\hline$>6 \mathrm{hrs}$ & & $437 / 1201(36.4)$ & $31.5(27.5,35.7)$ & $1.36(1.12,1.63)$ & $\longmapsto 1$ & 0.001 \\
\hline Timing of surgical source control & $1563 / 1595$ & & & & & $0.22^{*}$ \\
\hline $0-1 \mathrm{hr}$ & & $92 / 327(28.1)$ & $25.1(19.1,32.3)$ & 1 & & \\
\hline $1-3 \mathrm{hrs}$ & & $85 / 287(29.6)$ & $26.4(20.8,32.9)$ & $1.07(0.71,1.61)$ & $\longmapsto$ & 0.743 \\
\hline $3-6 \mathrm{hrs}$ & & $93 / 293(31.7)$ & $27.1(21.3,33.8)$ & $1.11(0.71,1.72)$ & 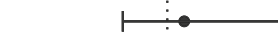 & 0.646 \\
\hline$>6 \mathrm{hrs}$ & & 240/656 (36.6) & $31.9(26.7,37.5)$ & $1.4(0.94,2.08)$ & $F$ & 0.102 \\
\hline Success of source control & $1563 / 1595$ & & & & & \\
\hline Not successful & & 179/262 (68.3) & $68.7(60.7,75.7)$ & 1 & & \\
\hline Successful & & $331 / 1301(25.4)$ & $20.2(16.5,24.5)$ & $0.12(0.08,0.16)$ & | & $<=0.001$ \\
\hline & & & & & 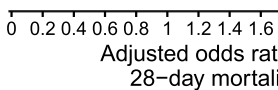 & \\
\hline \multicolumn{7}{|c|}{$\begin{array}{l}\text { Fig. } 2 \text { Effects of antimicrobial therapy and of surgical source control on 28-day mortality. Effects were tested in a logistic hierarchical linear model } \\
\text { with a random intercept adjusting for covariates. Risk-adjusted mortality estimates were obtained as predictive margins that were calculated for } \\
\text { the average of continuous variables and for the most common category of categorical variables. No. of patients gives the number of cases with } \\
\text { complete data compared to the total number of patients suitable for the respective analysis. }{ }^{*} \text { marks the p-value of the overall test of significance } \\
\text { for the categorical variables on timing conducted by a likelihood-ratio test, while the other p-values give the results of tests of single categories } \\
\text { against the reference category. Models adjusted for the following covariates: age and gender, origin of infection, location of the patient at the } \\
\text { onset of sepsis, focus of infection, microbiological confirmation of infection, study phase (trial vs. surveillance phase), and group the hospital was } \\
\text { randomized to (intervention vs. control) }\end{array}$} \\
\hline
\end{tabular}

among patients receiving vasopressors within the first $12 \mathrm{~h}$ (adjusted OR $=1.013$ [1.001, 1.026], $p=0.04$ ), but not among patients without shock (adjusted OR $=1.009$ $[0.984,1.035], p=0.481$, test of difference between odds-ratios: $p=0.778$ ). All subgroup analyses are presented in Fig. 3a, b.

\section{Sensitivity analyses}

When covariates on the severity of acute illness during the first $24 \mathrm{~h}$ after onset of sepsis were included, the effect of time to antimicrobial therapy remained largely unchanged compared to the primary analysis (Additional File 2: STable 8). Contrary to the primary analysis, time to source control showed a significant effect on 28-day mortality, when these additional covariates were included $(\mathrm{OR}=1.02[1.01,1.04] ; p=0.001)$.

\section{Discussion}

The key finding of our study is that a delay in time to treatment of infection is associated with an increase in 28-day mortality in patients with sepsis or septic shock. A delay in time to antibiotics increased the risk of death both among patients with and without septic shock and elevated the risk for progression from sepsis to septic shock. The relationship of timing of surgical source control and patient outcome was less consistent. When

(See figure on next page.)

Fig. 3 Test of effect moderation of timing of treatment in prespecified subgroups for time from onset of sepsis to start of antimicrobial therapy (panel a) and conduction of surgical source control (panel b) on 28-day mortality. OR: odds ratio per hour delay of treatment. Only cases with times between 0 and $48 \mathrm{~h}$ were considered. Effect moderation was tested by introducing individual interaction terms between respective effect moderator and the effect of timing of antimicrobial therapy or timing of surgical source control, respectively, in the logistic regression models. Regression models were calculated by logistic hierarchical linear models with a random intercept. No. of patients gives the number of cases with complete data compared to the total number of patients within the respective subgroup. Models adjusted for the following covariates: age and gender, origin of infection, location of the patient at the onset of sepsis, focus of infection, microbiological confirmation of infection, study phase (trial vs. surveillance phase), and group the hospital was randomized to (intervention vs. control). ICU: intensive care unit; IMC: intermediate care unit 


\section{a Effect of timing of antimicrobial therapy}

\begin{tabular}{|c|c|c|}
\hline Subgroups & o. of patients & $\begin{array}{r}\text { OR per hour } \\
(95 \% \mathrm{Cl})\end{array}$ \\
\hline All patients & $4659 / 4792$ & $1.019(1.01,1.028)$ \\
\hline \multicolumn{3}{|l|}{ Vasopressor use (first $12 \mathrm{hrs}$ ) } \\
\hline No & $1135 / 1186$ & $1.026(1.01,1.043)$ \\
\hline Yes & $3517 / 3595$ & $1.018(1.008,1.029)$ \\
\hline \multicolumn{3}{|l|}{ Origin of infection } \\
\hline Community acquired & $2205 / 2273$ & $1.021(1.005,1.037)$ \\
\hline Nosocomial (ICU/IMC) & $1072 / 1112$ & $1.013(0.998,1.028)$ \\
\hline Nosocomial (general ward) & $1382 / 1406$ & $1.023(1.007,1.038)$ \\
\hline \multicolumn{3}{|l|}{ Location at onset of sepsis } \\
\hline ICU/IMC & $2432 / 2513$ & $1.016(1.005,1.027)$ \\
\hline Ambulance service/emergency department & nt $1130 / 1159$ & $1.032(0.999,1.067)$ \\
\hline Operating room & $418 / 428$ & $1.054(1.018,1.092)$ \\
\hline General ward & 679/692 & $1.014(0.994,1.034)$ \\
\hline \multicolumn{3}{|l|}{ Infection microbiologically confirmed } \\
\hline No & $1230 / 1267$ & $1.015(0.998,1.032)$ \\
\hline Yes & $3429 / 3514$ & $1.02(1.01,1.031)$ \\
\hline \multicolumn{3}{|l|}{ Bacteremia } \\
\hline Gram positive & $791 / 806$ & $1.017(0.997,1.037)$ \\
\hline Gram negative & $694 / 712$ & $1.044(1.016,1.074)$ \\
\hline Other/several & $162 / 166$ & $1.059(1.005,1.116)$ \\
\hline No pathogen detected & $2225 / 2281$ & $1.014(1.001,1.027)$ \\
\hline No blood culture taken & $759 / 789$ & $1.014(0.995,1.033)$ \\
\hline \multicolumn{3}{|l|}{ Change of antimicrobial therapy within 5 days } \\
\hline No change & $2024 / 2067$ & $1.015(1.003,1.027)$ \\
\hline De-escalation & $599 / 642$ & $1.042(1.012,1.073)$ \\
\hline Escalation & $2034 / 2072$ & $1.017(1.002,1.032)$ \\
\hline \multicolumn{3}{|l|}{ Surgical source control conducted } \\
\hline No & $3007 / 3100$ & $1.019(1.008,1.03)$ \\
\hline Yes & $1652 / 1692$ & $1.017(1.001,1.034)$ \\
\hline
\end{tabular}

$b$ Effect of timing of surgical source control

$\begin{array}{lrr}\text { Subgroups } & \text { No. of patients } & \begin{array}{r}\text { OR per hour } \\ (95 \% \text { CI) }\end{array} \\ \text { All patients } & 1563 / 1595 & 1.008(0.997,1.02) \\ \text { Vasopressor use (first 12 hrs) } & & \\ \quad \text { No } & 237 / 244 & 1.009(0.984,1.035) \\ \quad \text { Yes } & 1323 / 1346 & 1.013(1.001,1.026) \\ \text { Origin of infection } & & \\ \text { Community acquired } & 771 / 795 & 1.01(0.993,1.027) \\ \quad \text { Nosocomial (ICU/IMC) } & 289 / 292 & 1.016(0.996,1.036) \\ \text { Nosocomial (general ward) } & 503 / 508 & 1(0.981,1.019) \\ \text { Location at onset of sepsis } & & \\ \text { ICU/IMC } & 671 / 682 & 1.003(0.989,1.018) \\ \text { Ambulance service/emergency department } & 327 / 337 & 1.01(0.982,1.039) \\ \text { Operating room } & 337 / 344 & 1.046(1.003,1.091) \\ \quad \text { General ward } & 228 / 232 & 1.01(0.985,1.035) \\ \text { Infection microbiologically confirmed } & & \\ \text { No } & 346 / 353 & 1.018(0.993,1.043) \\ \text { Yes } & 1217 / 1239 & 1.006(0.994,1.018) \\ \text { Bacteremia } & & \\ \text { Gram positive } & 223 / 224 & 0.999(0.975,1.023) \\ \text { Gram negative } & 200 / 206 & 0.993(0.961,1.027) \\ \text { Other/several } & 52 / 54 & 0.99(0.927,1.059) \\ \text { No pathogen detected } & 707 / 720 & 1.014(0.998,1.029) \\ \text { No blood culture taken } & 375 / 383 & 1.012(0.989,1.036) \\ \text { Change of antimicrobial therapy within } 5 \text { days } & & \\ \text { No change } & 703 / 715 & 1.002(0.985,1.02) \\ \text { De-escalation } & 154 / 162 & 1.029(0.997,1.062) \\ \text { Escalation } & 705 / 714 & 1.008(0.993,1.023) \\ \text { Success of source control } & & \\ \text { No } & 262 / 262 & 1.011(0.986,1.037) \\ \quad \text { Yes } & 1301 / 1333 & 1.006(0.992,1.019) \\ & & \end{array}$

Fig. 3 (See legend on previous page.)
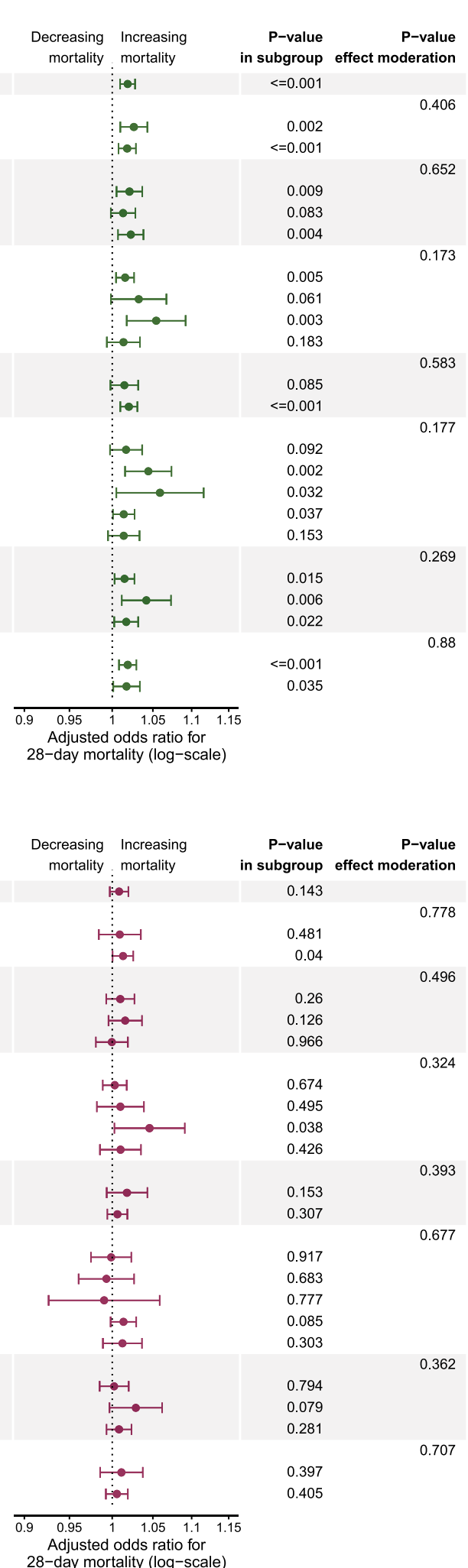
adjusted for confounders, it was only shown among patients with septic shock.

Previous research shows a large variation in the effect of timing of antimicrobial treatment on mortality in patients with sepsis. Two meta-analyses including studies until 2015 and 2016, respectively, revealed opposite results: Sterling et al. did not find a significant effect of timing on mortality by focussing on observed mortality [3]. Johnston et al. also included risk-adjusted effects and reported a significant decrease in odds of death in patients with early antimicrobial therapy [6]. Recent larger studies showed significant but small effects on mortality between 0.3 and $1.4 \%$ increased risk per hour $[19,20,26-28]$. This aligns with our findings of $0.4 \%$ increased risk of death per hour delay. This effect was significant both unadjusted and adjusted for possible confounders.

While most previous studies did not separate between sepsis and septic shock [5], our analyses showed a significant and similar effect of timing of antimicrobial treatment on mortality in both subgroups. Previous studies that compared patients with and without shock partly found no effect of delayed antimicrobials at all [29], smaller effects among patients without shock $[19,26]$, or virtually equal effects among both groups [20,27]. A recent study assessing all patients with infection admitted via the emergency department found a larger effect of delayed antimicrobials in a higher severity subgroup mostly defined by elevated lactate levels compared to the much larger group with lower severity at presentation [28]. Our data also show that the delay of antimicrobials increases the risk of progression to septic shock, as has also been reported in two other studies [30,31].

Weinberger et al. proposed a non-linear relation between delay of antimicrobials and mortality, claiming that there would be virtually no increase in mortality if delay was below six hours $[5,7]$. This argumentation has also been used to question the 1-h goal demanded by the sepsis guidelines of 2016 [5, 8]. Most previous studies were methodologically inappropriate to investigate this question, since they used emergency department triage as time zero $[4,5,17]$, where it is unclear how long sepsis persisted before that point in time. Using the documented occurrence of the first organ dysfunction as time zero allows more valid conclusions. Weinberger et al. suggested to calculate distinct adjusted estimates for the association between each hourly interval until antibiotics to test for a steady increase in mortality [5]. We argue that such pairwise comparisons between short time intervals are prone to be underpowered and biased by random error and unknown confounders. Likewise, we found that there was an increase of risk-adjusted mortality by $2.4 \%$ if treatment was delayed for 1 to $3 \mathrm{~h}$, but this difference was not significant. Explicitly testing for non-linearity of the effect of a continuous predictor is more informative than pairwise comparisons between intervals. Fractional polynomials are a method to test for non-linearity and to calculate an appropriate non-linear functional form for an effect in regression analyses [18, 19]. Using this method, we did not find significant evidence for a non-linear effect of delay of antimicrobials on mortality, which results in assuming a linear effect. There will be no conclusive evidence from observational studies, if it is safe or not safe to postpone anti-infective treatment for a short period of time among some patients with suspected sepsis. Responsible clinicians need to weigh up the competing risks of deterioration of a patient with sepsis vs. treating a patient possibly not having an infection with broad spectrum antibiotics. The new sepsis guidelines of 2021 reflect this reasoning by suggesting a time-limited course of rapid assessment of infectious vs. non-infectious causes among patients with possible sepsis without shock and, if concern for infection persists, the administration of antimicrobials within $3 \mathrm{~h}$ [2]. Delays in treatment are usually not based on purposeful clinical decision-making but on lacking awareness, late recognition of clinical deterioration, shortcomings in communication and other organizational barriers to early diagnosis and treatment [38]. Therefore, our results support initiatives to raise awareness for sepsis as a medical emergency.

Studies on delay in surgical source control were mostly conducted among patients with single disease entities such as necrotizing fasciitis, peptic ulcer perforation, cholangitis, infected pancreatic necrosis or urinary tract infections and mostly had small samples with heterogeneous disease severity [2, 10-12, 32-34]. Two recent large studies among patients with sepsis [13] and septic shock [14] did not find a significant increase in mortality by delayed source control. In unadjusted analyses, we found a significant effect of timing of source control on mortality, while adjusted for possible confounders this effect only proved to be significant among patients with septic shock. Success of source control itself is a strong predictor of survival $[35,36]$. Our study additionally found a delay in source control to decrease the chances of success, but again only in the unadjusted analyses and not in the analysis adjusted for confounders. Therefore, the sensitivity of effects of timing of treatment on outcome to confounder adjustment, which has been extensively discussed regarding antibiotics [5], also applies to analyses of timing of source control.

Additionally, delays in surgical source control in relation to risk of progression to shock within 12 to $24 \mathrm{~h}$ after sepsis onset showed an unexpected reversed U-shaped curve. Such a U-shape may be the result of treatment 
decisions prior to surgery as physicians may decisively postpone surgery in patients, which might need or might benefit from additional stabilization of hemodynamics and physiologic status prior to surgical source control [37]. Likewise, surgeons might have delayed intervention due to diagnostic uncertainty in patients with vague or subtle symptoms, which might have had better outcomes. Therefore, on the one hand, our results indicate that early surgical source control is warranted in patients with sepsis-especially in patients with shock. On the other hand, they hint at the complexities of the dynamics of symptoms, illness progression, and clinical decisionmaking that cannot be fully measured or operationalized in an observational study.

This study has several strengths. It is based on a large sample of prospectively included patients with sepsis combining data on both timing of antimicrobial therapy and timing of source control. It is less biased by methodological flaws, since it is one of the few studies using physiological criteria of sepsis onset as time zero, while most previous studies-especially those with large sample sizes-used timing of emergency department triage or beginning of treatment [3-6, 19, 26, 27]. It is also one of the few studies using a standardized follow-up period instead of hospital mortality. Most previous studies also did not adjust adequately for possible confounders [5]. In our study, the effects of delayed antimicrobial therapy were significant both without risk adjustment as well as with adjustment including presenting symptoms and illness severity, suggesting that the effect of timing was not merely an artefact of statistical adjustment [8].

The study also has limitations. Definition of time zero by the review of physiological parameters in patient charts has a problem of imperfect objectivity and reliability due to incomplete measurement or documentation in routine care [39]. This might have biased the effect of delay of treatment found in our study. Since ordering time has not been assessed in our study, we were not able to separate between time of recognition of sepsis and time of antimicrobial treatment [17]. Also, sensitivity of pathogens to the first antibiotics was not systematically assessed and could therefore not be analysed. Little information was available about pre-existing risk-factors such as comorbidities or presenting signs and symptoms like vital signs and laboratory values at onset of sepsis, which are two important gaps to the risk-adjustment [5]. A delay in source control might be due to the need to stabilize patients first, but we had no sufficient data to identify respective patients in our analysis. Our study was conducted among German hospitals, only, but results are comparable to international studies [19, 20, 26, 30]. This study did only include patients with sepsis in need of critical care. Therefore, it was not possible to investigate possibly preventive effects of anti-infective interventions before occurrence of infection related organ dysfunctions. In addition, the findings of this study cannot be applied to less severely ill patients not needing intensive care. Study physicians were not blinded to outcome when evaluating the success of surgical source control, which might have caused a bias of judgement of success.

\section{Conclusions}

Our findings that delays in antimicrobial treatment after onset of sepsis and surgical source control after onset of septic shock were associated with increased 28-day mortality, increased the risk of progression from sepsis to septic shock and decreased probability of successful source control, suggest that for the management of sepsis time matters both for antimicrobial therapy and source control. Also patients, who are not yet in septic shock, profit from early anti-infective treatment since it can prevent further deterioration.

\section{Abbreviations}

ICU: Intensive care unit; IMC: Intermediate care unit; MEDUSA trial: Medical Education for Sepsis Source Control and Antibiotics trial; OR: Odds ratio.

\section{Supplementary Information}

The online version contains supplementary material available at https://doi. org/10.1186/s13054-022-03901-9.

Additional file 1. Supplemental Figures. SFigure 1. Calibration belt of the risk-adjustment-model for 28-day-mortality. The figure shows observed 28-day mortality (y-axis) compared to model based estimates of expected 28-day mortality (x-axis). SFigure 2. Flow-diagram of the study. SFigure 3. Panel a: Timing of start of antimicrobial treatment in relation to onset of sepsis. Panel b: Timing of surgical source control in relation to onset of sepsis. Panel c: Cumulative proportion of patients receiving antimicrobial treatment after onset of sepsis within the first 48 hours. Panel $d$ : Cumulative proportion of patients receiving surgical source control after onset of sepsis within the first 48 hours. SFigure 4. Crude mortality and predicted mortality depending on success of surgical source control. Presented are the risk (bars) and predicted risk (lines) across a range of time after onset of sepsis. Bold lines present the predicted risk with 95\% confidence interval for a typical patient from a model adjusting for covariates, dotted lines present the predicted risk with 95\% confidence interval from a model without adjusting for covariates. The effect of timing was tested for linearity by fractional polynomials at significance level 0.05 ; timing was treated as linear, since no significant deviation from linearity was found. Risk-adjusted OR with 95\% Cl: 0.991 [0.978, 1.005], $p=0.197$; raw OR with $95 \%$ Cl: $0.982[0.971,0.994], p=0.003 . N=1595$ cases did undergo surgical source control within 48 hours, of which 1592 cases had complete data on outcome and covariates for analysis. The risk-adjustment model involved the following covariates: age and gender, origin of infection, location of the patient at the onset of sepsis, focus of infection, microbiological confirmation of infection, study phase (trial vs. surveillance phase), and group the hospital was randomized to (intervention vs. control).

Additional file 2. Supplemental Tables. STable 1. Risk-adjustmentmodel for 28-day mortality excluding variables on severity of critical illness. STable 2. Risk-adjustment-model for 28-day mortality including variables on severity of critical illness. STable 3. Characteristics of participating hospitals. STable 4. Description of cases with timing of antimicrobial therapy before sepsis onset or after more than 48 hours. STable $\mathbf{5}$. 
Description of cases with timing of surgical source control before sepsis onset or after more than 48 hours. STable 6 . Analysis of combined effects of delay in antimicrobial therapy and delay in surgical source control. STable 7. Effects of indicators of quality of anti-infective therapy on hospital length-of-stay of hospital survivors. STable 8. Sensitivity analysis on effects of indicators on quality of anti-infective therapy on 28-day-mortality adjusting for covariates including measures on severity of critical illness.

\section{Acknowledgements}

Collaborating author names (MEDUSA study group). University Hospital RWTH Aachen. Department of Intensive Care Medicine: Gernot Marx, Achim Schindler, Tobias Schürholz; Ilm-Kreis-Kliniken Arnstadt. Department of Anesthesiology and Intensive Care Medicine: Heike Schlegel-Höfner, Gunther Lehmann, Annett Sander, Steffen Friese, Christian Scholz; Helios Hospital Aue. Department of Anesthesiology and Intensive Care Medicine: Pia Fischer; Zentralklinik Bad Berka GmbH. Department of Anaesthesia and Intensive Care Medicine: Christina Fuchs, Lutz Becher, Norbert Salewsky, Torsten Schreiber; Charité Berlin. Department of Anesthesiology and Operative Intensive Care Medicine: Anton Goldmann, Didier Keh, Katrin Schmid; Hufeland-Klinikum Bad Langensalza. Department of Anesthesiology and Intensive Care Medicine: Winfried Menning, Renate Steuckart; Bundeswehrkrankenhaus Berlin. Department of Anesthesiology and Intensive Care Medicine: Robert Barz, Karin Dey, Meike Fahrenholz, Martin Müller; Vivantes Klinikum Neukölln Berlin. Department of Anesthesiology, Surgical Intensive Care Medicine, and Pain Therapy: Herwig Gerlach, Susanne Toussaint; Helios Hospital Berlin-Buch. Department of Intensive Care Medicine: Jörg Brederlau; Ev. Hospital Bielefeld. Department of Anesthesiology, Emergency and Intensive Care Medicine, and Pain Therapy: Friedhelm Bach, Dirk Buschmann, Ingo Gummelt, J. Hoeschen, Marion Klaproth, Ina Vedder; HELIOS-Hospital St. Josefs-Hospital Bochum-Linden. Department of Anesthesiology: Ulrike Bachmann-Holdau; St. Georg Hospital Eisenach. Department of Anesthesiology and Intensive Care Medicine: Jürgen Eiche, Rolf Hauschild; Hospital Rudolf Elle, Eisenberg. Department of Anesthesiology and Intensive Care Medicine: Martina Lange, Davia Herrmann-Karbaum; Helios-Hospital Emil-von Behring. Department of Interdisciplinary Intensive Care and Emergency Medicine: Annette Lubasch, Marcus Rücker; Helios-Hospital Erfurt. Department of Anesthesiology and Intensive Care Medicine: Christian Icke, Alexander Lucht, Andreas Meier-Hellmann, Jan Wagner; Catholic Hospital St. Johann Nepomuk Erfurt. Department of Anesthesiology and Intensive Care Medicine: Olaf Arnold, Steffen Kästner, Tobias Clausen; Hospital Friedberg. Department of Internal Medicine: Michael Sternkopf, Robert Voswinckel; SRH Waldklinikum Gera. Department of Anesthesiology and Intensive Care Medicine: T. Benndorf, Christel Eiserloh, Gerhard Kuhnle, Mathias Koch; University Hospital Greifswald. Department of Anesthesiology and Intensive Care Medicine: Manuela Gerber, Matthias Gründling, Liane Guderian, Sven-Olaf Kuhn, Christian Scheer; Hospital IImenau. Department of Anesthesiology and Intensive Care Medicine: Gerd Scheiber; Jena University Hospital, Center for Sepsis Control \& Care/Department of Anesthesiology and Intensive Care Medicine: Claudia Matthäus-Krämer, Bernhard Poidinger; University Hospital Kiel. Department of Anesthesiology and Intensive Care Medicine: Stefanie D'Aria, Thees Lemke, Birgit Michaelsen, Dirk Schädler, Nina Schulz-Ruhtenberg, Norbert Weiler; Hospital Landshut-Achdorf. Department of Anesthesiology and Surgical Intensive Care Medicine: Martin Anetseder, Zoran Textor; University Hospital Leipzig. Department of Anesthesiology and Intensive Care Medicine: Udo Kaisers, Philipp Simon; University of Leipzig. Institute of Medical Informatics, Statistics and Epidemiology: Matthias Löbe, Frank Meineke, Christine Pausch, Christoph Engel; Hospital Meiningen. Department of Intensive Care and Emergency Medicine: Georg Braun, Nicole Jensen, Werner Gegenfurtner, Alexander Meinhardt, Robert Schmitt, Andrea Teichert; Saale-Unstrut-Hospital Naumburg. Department of Anesthesiology and Intensive Care Medicine: Klaus-Dieter Becker; Hospital Oldenburg. Department of Anesthesiology, Intensive Care Medicine, Emergency Medicine, and Pain Therapy: Anja Diers, Florian Jelschen, Andreas Weyland; Thüringen-Klinik Pößneck. Department of Anesthesiology and Intensive Care Medicine: Frieder Knebel, Thomas Kupfer; Asklepios Hospital Radeberg. Department of Intensive Care and Emergency Medicine: Rüdinger Sinz; Thüringen-Kliniken Saalfeld. Department of Anesthesiology, Intensive Care Medicine, and Pain Therapy: Petra Bautz, Annemarie Fischer; Ev. Jung-Stilling Hospital Siegen. Department of Anesthesiology, Intensive Care, and Emergency Medicine: Armin Seibel, Christoph Fleischhacker; University Hospital Tübingen. Department of Anesthesiology: Helene Häberle, Philipp Henn, Friederike Mezger, Peter Rosenberger; University Hospital Tübingen. Dept of Internal Medicine: Reimer Riessen, Silvia Ziegler; University Hospital Medical School Ulm. Clinic of Anaesthesiology: Eberhard Barth, Hendrik Bracht, I. Heymann, A. Hinder, R. Sens, Manfred Weiss; Hufeland Hospital Weimar. Department of Anesthesiology and Intensive Care Medicine: Christof Lascho, Henriette Micke, Falk Schmidt; Helios Hospital Wuppertal. Department of Intensive Care Medicine: Stefanie Schilling, Gabriele Wöbker.

\section{Authors' contributions}

$D S, H R, F B, D O T$ and KR contributed to conception of the work. DS conducted the analysis. DS and HR drafted the manuscript. HR, FB, DOT, KR, FB, HG, ML, $J C M, P S$, and MW contributed to interpretation of the data and critically revised the manuscript for intellectual content. All authors gave a final approval of the version to be published and agree to be accountable for their respective contributions and ensure that questions related to the accuracy or integrity of any part of the work are appropriately investigated and resolved. $\mathrm{DS}, \mathrm{FB}$, and DOT have verified the underlying data. All authors read and approved the final manuscript.

\section{Funding}

Open Access funding enabled and organized by Projekt DEAL. The study was funded by the German Federal Ministry of Education and Research via the integrated research and treatment center "Center for Sepsis Control and Care" (FKZ 01EO1002). The funding source had no influence on the conduction of the study or publication of the results.

\section{Availability of data and materials}

All data requests should be submitted to Dr. Bloos (Frank.Bloos@med.uni-jena. de) for consideration. Access to the anonymised data might be granted following review by the Center for Sepsis Control and Care (CSCC) and the Jena University Hospital.

\section{Declarations}

\section{Ethics approval and consent to participate}

It was approved by the local ethics committees at each participating hospital. The need for informed consent was waived since randomization was performed on the cluster level, and the interventions comprised quality improvement measures. Involved ethical bodies: Ethics committee of the University Hospital Jena (2910-08/10). Ethics committee of the "Ärztekammer Nordrhein" (2010403). Ethics committee of the "Ärztekammer Westfalen-Lippe" (2010-518b-S). Ethics committee of the "Landesärztekammer Baden-Würtemberg" (B-F2010-056). Ethics committee of the "Landesärztekammer Bayern" (7/10284). Ethics committee of the "Landesärztekammer Hessen" (MC 245/2010). Ethics committee of the "Landesärztekammer Niedersachsen" (Ar/211/2010). Ethics committee of the "Landesärztekammer Saarland" (195/10). Ethics committee of the "Landesärztekammer Sachsen" (EK-BR-51/10-1). Ethics committee of the Medical Faculty Leipzig (324-10-08112010). Ethics committee of the "Landesärztekammer Sachsen-Anhalt" (33/10). Ethics committee of the "Landesärztekammer Thüringen" (38831/2010/109). Ethics committee of the Medical Faculty Greifswald (BB 129/10). Ethics committee of the Medical Faculty Kiel (B 204/11). Ethics committee of the Medical Faculty Tübingen (556/2010BO2). Ethics committee of the University Ulm (295/10). Ethics committee of the University Witten-Herdecke (90/2010).

\section{Consent for publication}

\section{Not applicable.}

\section{Competing interests}

Dr. Rüddel has nothing to disclose. Dr. Bloos reports grants from German Federal Ministry of Education and Research to his institution, during and outside the conduct of the study; personal fees from Baxter, outside the submitted work, and receipt of kits for a clinical trial from Assoc. of CapeCods, outside the submitted work. Dr. Thomas-Rüddel reports grants from BMBF to his institution, outside the submitted work..Dr. Reinhart is shareholder with less of $0.5 \%$ of InflaRx NV a Jena /Germany based Biotech Company that evaluates 
a immunmodulatory approach for the adjunctive treatment of COVID-19. Dr. Bach has nothing to disclose. Dr. Gerlach has nothing to disclose. Dr. Lindner has nothing to disclose. Dr. Marshall reports consulting fees from Gilead Pharma, support for traveling to the WHO Covid-19 meeting by Bill and Melinda Gates Foundation, personal fees from AM Pharma for participation on a data safety monitoring board, being chair of the International Forum for Acute Care Trialists (unpaid), and being co-chair of the WHO Working Group on Clinical Characterization and Management of Covid-19 (unpaid), all outside the submitted work. Dr. Simon has nothing to disclose. Dr. Weiss has nothing to disclose. Dr. Schwarzkopf reports grants from German Federal Ministry of Education and Research to his institution, during the conduct of the study.

\section{Author details}

${ }^{1}$ Integrated Research and Treatment Center - Center for Sepsis Control and Care (CSCC), Jena University Hospital, Am Klinikum 1, 07747 Jena, Germany. ${ }^{2}$ Department of Anaesthesiology and Intensive Care Medicine, Jena University Hospital, Am Klinikum 1, 07747 Jena, Germany. ${ }^{3}$ Department of Anaesthesiology and Operative Intensive Care Medicine (CCM, CVK), Charité Universitätsmedizin Berlin, Corporate Member of Freie Universität Berlin, Humboldt-Universität Zu Berlin, Augustenburger Platz 1, 13353 Berlin, Germany. ${ }^{4}$ Berlin Institute of Health, Campus Virchow-Klinikum, Anna-Louisa-Karsch-Straße 2, 10178 Berlin, Germany. ${ }^{5}$ Department for Infectious Diseases, Protestant Hospital of Bethel Foundation University Hospital, University of Bielefeld, Bethesdaweg 10, 33617 Bielefeld, Germany. ${ }^{6}$ Department for Anaesthesia, Intensive Care Medicine and Pain Management, Vivantes - Klinikum Neukoelln, Rudower Strasse 48, 12351 Berlin, Germany. ${ }^{7}$ Department of Anaesthesiology and Intensive Care Medicine, University Hospital Schleswig-Holstein, Campus Kiel, Arnold-Heller-Straße 3, 24105 Kiel, Germany. ${ }^{8}$ Li Ka Shing Knowledge Institute, St. Michael's Hospital, University of Toronto, 209 Victoria St, Toronto, ON M5B 1T8, Canada. ${ }^{9}$ Department of Anaesthesiology and Intensive Care, University of Leipzig Medical Centre, Liebigstraße 20, 04103 Leipzig, Germany. ${ }^{10}$ Klinik Für Anästhesiologie Und Intensivmedizin, Universitätsklinikum Ulm, Albert-Einstein-Allee 23, 89081 Ulm, Germany. ${ }^{11}$ Center for Infectious Diseases and Infection Control, Jena University Hospital, Am Klinikum 1, 07747 Jena, Germany. ${ }^{12}$ Department of Intensive Care Medicine, University Hospital RWTH Aachen, Aachen, Germany. ${ }^{13}$ Department of Anesthesiology and Intensive Care Medicine, IIm-Kreis-Kliniken Arnstadt, Arnstadt, Germany. ${ }^{14}$ Department of Anesthesiology and Intensive Care Medicine, Helios Hospital Aue, Bad Schlema, Germany. ${ }^{15}$ Department of Anaesthesia and Intensive Care Medicine, Zentralklinik Bad Berka GmbH Bad Berka, Germany. ${ }^{16}$ Department of Anesthesiology and Operative Intensive Care Medicine, Charité Berlin, Berlin, Germany. ${ }^{17}$ Department of Anesthesiology and Intensive Care Medicine, Hufeland-Klinikum Bad Langensalza, Bad Langensalza, Germany. ${ }^{18}$ Department of Anesthesiology and Intensive Care Medicine, Bundeswehrkrankenhaus Berlin, Berlin, Germany. ${ }^{19}$ Department of Anesthesiology, Surgical Intensive Care Medicine, and Pain Therapy, Vivantes Klinikum Neukölln Berlin, Berlin, Germany. ${ }^{20}$ Department of Intensive Care Medicine, Helios Hospital Berlin-Buch, Berlin, Germany. ${ }^{21}$ Department of Anesthesiology, Emergency and Intensive Care Medicine, and Pain Therapy, Ev. Hospital Bielefeld, Bielefeld, Germany. ${ }^{22}$ Department of Anesthesiology, HELIOS-Hospital St. Josefs-Hospital Bochum-Linden, Bochum, Germany. ${ }^{23}$ Department of Anesthesiology and Intensive Care Medicine, St. Georg Hospital Eisenach, Eisenach, Germany. ${ }^{24}$ Eisenberg. Department of Anesthesiology and Intensive Care Medicine, Hospital Rudolf Elle, Thuringen, Germany. ${ }^{25}$ Department of Interdisciplinary Intensive Care and Emergency Medicine, Helios-Hospital Emil-von Behring, Berlin, Germany. ${ }^{26}$ Department of Anesthesiology and Intensive Care Medicine, Helios-Hospital Erfurt, Erfurt, Germany. ${ }^{27}$ Department of Anesthesiology and Intensive Care Medicine, Catholic Hospital St. Johann Nepomuk Erfurt, Erfurt, Germany. ${ }^{28}$ Department of Internal Medicine, Hospital Friedberg, Friedberg, Germany. ${ }^{29}$ Department of Anesthesiology and Intensive Care Medicine, SRH Waldklinikum Gera, Gera, Germany. ${ }^{30}$ Department of Anesthesiology and Intensive Care Medicine, University Hospital Greifswald, Greifswald, Germany. ${ }^{31}$ Department of Anesthesiology and Intensive Care Medicine, Hospital IImenau, IImenau, Germany. ${ }^{32}$ Center for Sepsis Control \& Care/Department of Anesthesiology and Intensive Care Medicine, Jena University Hospital, Jena, Germany. ${ }^{33}$ Department of Anesthesiology and Intensive Care Medicine, University Hospital Kiel, Kiel, Germany. ${ }^{34}$ Department of Anesthesiology and Surgical Intensive Care Medicine, Hospital Landshut-Achdorf, Landshut, Germany. ${ }^{35}$ Department of Anesthesiology and Intensive Care Medicine, University Hospital Leipzig, Leipzig, Germany. ${ }^{36}$ Institute of Medical Informatics, Statistics and Epidemiology, University of Leipzig, Leipzig, Germany. ${ }^{37}$ Department of Intensive Care and Emergency Medicine, Hospital Meiningen, Meiningen, Germany. ${ }^{38}$ Department of Anesthesiology and Intensive Care Medicine, Saale-Unstrut-Hospital Naumburg, Naumburg, Germany. ${ }^{39}$ Department of Anesthesiology, Intensive Care Medicine, Emergency Medicine, and Pain Therapy, Hospital Oldenburg, Oldenburg, Germany. ${ }^{40}$ Department of Anesthesiology and Intensive Care Medicine, Thüringen-Klinik Pößneck, Pößneck, Germany. ${ }^{41}$ Department of Intensive Care and Emergency Medicine, Asklepios Hospital Radeberg, Radeberg, Germany. ${ }^{42}$ Department of Anesthesiology, Intensive Care Medicine, and Pain Therapy, Thüringen-Kliniken Saalfeld, Saalfeld, Germany. ${ }^{43}$ Department of Anesthesiology, Intensive Care, and Emergency Medicine, Ev. Jung-Stilling Hospital Siegen, Siegen, Germany. ${ }^{44}$ Department of Anesthesiology, University Hospital Tübingen, Tübingen, Germany. ${ }^{45}$ Department of Internal Medicine, University Hospital Tübingen, Tübingen, Germany. ${ }^{46}$ University Hospital Medical School Ulm. Clinic of Anaesthesiology, Ulm, Germany. ${ }^{47}$ Department of Anesthesiology and Intensive Care Medicine, Hufeland Hospital Weimar, Weimar, Germany. ${ }^{48}$ Department of Intensive Care Medicine, Helios Hospital Wuppertal, Wuppertal, Germany.

\section{Received: 25 October 2021 Accepted: 16 January 2022}

Published online: 28 February 2022

\section{References}

1. Singer M, Deutschman CS, Seymour CW, Shankar-Hari M, Annane D, Bauer M, Bellomo R, Bernard GR, Chiche JD, Coopersmith CM, et al. The third international consensus definitions for sepsis and septic shock (sepsis-3). JAMA. 2016;315(8):801-10.

2. Evans L, Rhodes A, Alhazzani W, Antonelli M, Coopersmith CM, French C, Machado FR, McIntyre L, Ostermann M, Prescott HC, et al. Surviving sepsis campaign: international guidelines for management of sepsis and septic shock 2021. Intensive Care Med. 2021:47(11):1181-247.

3. Sterling SA, Miller WR, Pryor J, Puskarich MA, Jones AE. The impact of timing of antibiotics on outcomes in severe sepsis and septic shock: a systematic review and meta-analysis. Crit Care Med. 2015;43(9):1907-15.

4. Rothrock SG, Cassidy DD, Barneck M, Schinkel M, Guetschow B, Myburgh C, Nguyen L, Earwood R, Nanayakkara PWB, Nannan Panday RS et al. Outcome of immediate versus early antibiotics in severe sepsis and septic shock: a systematic review and meta-analysis. Ann Emerg Med. 2020.

5. Weinberger J, Rhee C, Klompas M. A critical analysis of the literature on time-to-antibiotics in suspected sepsis. J Infect Dis. 2020;222(Supplement _2):S110-8.

6. Johnston ANB, Park J, Doi SA, Sharman V, Clark J, Robinson J, Crilly $J$. Effect of immediate administration of antibiotics in patients with sepsis in tertiary care: a systematic review and meta-analysis. Clin Ther. 2017;39(1):190-202.e196.

7. Rhee C, Heil EL. Toward more rational time-to-antibiotic metrics for suspected sepsis. Crit Care Med. 2021;49(5).

8. Klompas M, Calandra T, Singer M. Antibiotics for sepsis-finding the equilibrium. JAMA. 2018;320(14):1433-4.

9. Rhodes A, Evans LE, Alhazzani W, Levy MM, Antonelli M, Ferrer R, Kumar A, Sevransky JE, Sprung CL, Nunnally ME, et al. Surviving sepsis campaign: international guidelines for management of sepsis and septic shock: 2016. Intensive Care Med. 2017;43(3):304-77.

10. Buck DL, Vester-Andersen M, Moller MH. Danish clinical register E: surgical delay is a critical determinant of survival in perforated peptic ulcer. $\mathrm{Br} J$ Surg. 2013;100(8):1045-8.

11. Chao W-N, Tsai C-F, Chang H-R, Chan K-S, Su C-H, Lee Y-T, Ueng K-C, Chen C-C, Chen S-C, Lee M-C. Impact of timing of surgery on outcome of Vibrio vulnificus-related necrotizing fasciitis. Am J Surg. 2013;206(1):32-9.

12. Azuhata T, Kinoshita K, Kawano D, Komatsu T, Sakurai A, Chiba Y, Tanjho K. Time from admission to initiation of surgery for source control is a critical determinant of survival in patients with gastrointestinal perforation with associated septic shock. Crit Care. 2014;18(3):R87.

13. Martínez ML, Ferrer R, Torrents E, Guillamat-Prats R, Gomà G, Suárez D, Álvarez-Rocha L, Pozo Laderas JC, Martín-Loeches I, Levy MM et al. Impact of source control in patients with severe sepsis and septic shock. Crit Care Med. 2017;45(1). 
14. Kim H, Chung SP, Choi S-H, Kang GH, Shin TG, Kim K, Park YS, Han KS, Choi HS, Suh GJ, et al. Impact of timing to source control in patients with septic shock: a prospective multi-center observational study. J Crit Care. 2019;53:176-82.

15. Bloos F, Rüddel H, Thomas-Rüddel D, Schwarzkopf D, Pausch C, Harbarth S, Schreiber T, Gründling M, Marshall J, Simon P, et al. Effect of a multifaceted educational intervention for anti-infectious measures on sepsis mortality: a cluster randomized trial. Intensive Care Med. 2017;43(11):1602-12.

16. Brunkhorst FM, Engel C, Bloos F, Meier-Hellmann A, Ragaller M, Weiler $\mathrm{N}$, Moerer O, Gruendling M, Oppert M, Grond S, et al. Intensive insulin therapy and pentastarch resuscitation in severe sepsis. N Engl J Med. 2008;358(2):125-39.

17. Taylor SP, Anderson WE, Beam K, Taylor B, Ellerman J, Kowalkowski MA. The association between antibiotic delay intervals and hospital mortality among patients treated in the emergency department for suspected sepsis. Crit Care Med. 2021;49(5):741-7.

18. Sauerbrei W, Royston P, Binder H. Selection of important variables and determination of functional form for continuous predictors in multivariable model building. Stat Med. 2007;26(30):5512-28.

19. Seymour CW, Gesten F, Prescott HC, Friedrich ME, Iwashyna TJ, Phillips GS, Lemeshow S, Osborn T, Terry KM, Levy MM. Time to treatment and mortality during mandated emergency care for sepsis. N Engl J Med. 2017;376(23):2235-44

20. Ferrer R, Martin-Loeches I, Phillips G, Osborn TM, Townsend S, Dellinger RP, Artigas A, Schorr C, Levy MM. Empiric antibiotic treatment reduces mortality in severe sepsis and septic shock from the first hour: results from a guideline-based performance improvement program. Crit Care Med. 2014;42(8):1749-55.

21. Motzkus CA, Luckmann R. Does infection site matter? A systematic review of infection site mortality in sepsis. J Intensive Care Med. 2016;32(8):473-9.

22. Assinger A, Schrottmaier WC, Salzmann M, Rayes J. Platelets in sepsis: an update on experimental models and clinical data. Front Immunol. 2019;10:1687

23. Kaplan $\sqcup$, Frangos S. Clinical review: acid-base abnormalities in the intensive care unit—part II. Crit Care. 2005;9(2):198-203.

24. Singer M. Antibiotics for sepsis: does each hour really count, or is it incestuous amplification? Am J Respir Crit Care Med. 2017;196(7):800-2.

25. Jakobsen JC, Gluud C, Wetterslev J, Winkel P. When and how should multiple imputation be used for handling missing data in randomised clinical trials-a practical guide with flowcharts. BMC Med Res Methodol. 2017;17(1):162.

26. Liu VX, Fielding-Singh V, Greene JD, Baker JM, Iwashyna TJ, Bhattacharya J, Escobar GJ. The timing of early antibiotics and hospital mortality in sepsis. Am J Respir Crit Care Med. 2017;196(7):856-63.

27. Peltan ID, Brown SM, Bledsoe JR, Sorensen J, Samore MH, Allen TL, Hough $\mathrm{CL}$. ED door-to-antibiotic time and long-term mortality in sepsis. Chest. 2019;155(5):938-46.

28. Han X, Spicer A, Carey KA, Gilbert ER, Laiteerapong N, Shah NS, Winslow C, Afshar M, Kashiouris MG, Churpek MM. Identifying high-risk subphenotypes and associated harms from delayed antibiotic orders and delivery. Crit Care Med. 2021;49(10):1694-705.

29. Abe T, Kushimoto S, Tokuda Y, Phillips GS, Rhodes A, Sugiyama T, Komori A, Iriyama H, Ogura H, Fujishima S, et al. Implementation of earlier antibiotic administration in patients with severe sepsis and septic shock in Japan: a descriptive analysis of a prospective observational study. Crit Care (London, England). 2019;23(1):360.

30. Whiles BB, Deis AS, Simpson SQ. Increased time to initial antimicrobial administration is associated with progression to septic shock in severe sepsis patients. Crit Care Med. 2017;45(4):623-9.

31. Bisarya R, Song X, Salle J, Liu M, Patel A, Simpson SQ. Antibiotic timing and progression to septic shock among patients in the ED with suspected infection. Chest; 2021.

32. Karvellas CJ, Abraldes JG, Zepeda-Gomez S, Moffat DC, Mirzanejad Y, Vazquez-Grande G, Esfahani EK, Kumar A. The cooperative antimicrobial therapy of septic shock database research G: the impact of delayed biliary decompression and anti-microbial therapy in 260 patients with cholangitis-associated septic shock. Aliment Pharmacol Ther. 2016;44(7):755-66.

33. Haas CR, Li G, Hyams ES, Shah O. Delayed decompression of obstructing stones with urinary tract infection is associated with increased odds of death. J Urol. 2020;204(6):1256-62.
34. Boxhoorn L, van Dijk SM, van Grinsven J, Verdonk RC, Boermeester MA, Bollen TL, Bouwense SAW, Bruno MJ, Cappendijk VC, Dejong CHC, et al. Immediate versus postponed intervention for infected necrotizing pancreatitis. N Engl J Med. 2021;385(15):1372-81.

35. Tellor B, Skrupky LP, Symons W, High E, Micek ST, Mazuski JE. Inadequate source control and inappropriate antibiotics are key determinants of mortality in patients with intra-abdominal sepsis and associated bacteremia. Surg Infect (Larchmt). 2015;16(6):785-93.

36. Lagunes L, Rey-Pérez A, Martín-Gómez MT, Vena A, de Egea V, Muñoz P, Bouza E, Díaz-Martín A, Palacios-García I, Garnacho-Montero J, et al. Association between source control and mortality in 258 patients with intra-abdominal candidiasis: a retrospective multi-centric analysis comparing intensive care versus surgical wards in Spain. Eur J Clin Microbiol Infect Dis. 2017;36(1):95-104.

37. Opal SM. Source control in sepsis urgent or not so fast? Crit Care Med. 2017:45(1):130-2.

38. Goodwin APL, Srivastava V, Shotton H, Protopapa K, Butt A, Mason M. Just say sepsis! A review of the process of care received by patients with sepsis. In.; 2015.

39. Rhee C, Brown SR, Jones TM, O'Brien C, Pande A, Hamad Y, Bulger AL, Tobin KA, Massaro AF, Anderson DJ, et al. Variability in determining sepsis time zero and bundle compliance rates for the centers for medicare and medicaid services SEP-1 measure. Infect Control Hosp Epidemiol. 2018;39(8):994-6.

\section{Publisher's Note}

Springer Nature remains neutral with regard to jurisdictional claims in published maps and institutional affiliations.

Ready to submit your research? Choose BMC and benefit from:

- fast, convenient online submission

- thorough peer review by experienced researchers in your field

- rapid publication on acceptance

- support for research data, including large and complex data types

- gold Open Access which fosters wider collaboration and increased citations

- maximum visibility for your research: over $100 \mathrm{M}$ website views per year

At BMC, research is always in progress.

Learn more biomedcentral.com/submissions 